\title{
A New Two-Step Anesthesia for 23- or 25-Gauge Vitrectomy Surgery: A Prospective, Randomized Clinical Trial
}

\author{
Hua Fan ${ }^{\mathrm{a}}$ Zhuyun Qian ${ }^{\mathrm{a}}$ Radouil Tzekov ${ }^{\mathrm{b}}$ Dong Lin ${ }^{\mathrm{a}}$ Hongxia Wang ${ }^{\mathrm{a}}$ \\ Wensheng $\mathrm{Li}^{\mathrm{a}, \mathrm{c}}$ \\ ${ }^{a}$ Department of Retina, Shanghai Aier Eye Hospital, Shanghai, China; ${ }^{b}$ Department of Ophthalmology, University of

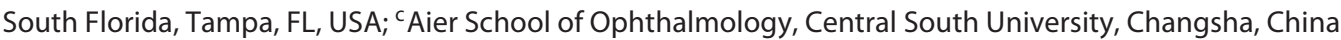

\section{Keywords}

Vitrectomy · Retrobulbar anesthesia - Peribulbar anesthesia • Two-step anesthesia

\begin{abstract}
Objective: To investigate the safety and efficacy of topical anesthesia combined with subconjunctival anesthesia (termed two-step anesthesia) for 23- or 25-gauge pars plana vitrectomy or other posterior segment surgery. Methods: Patients ( $n=90$ ) requiring 23-/25-gauge vitrectomy or other posterior segment surgery were randomized into 3 groups. Group 1 received peribulbar anesthesia, group 2 received retrobulbar anesthesia and group 3 received two-step anesthesia. A 5-point visual analog pain scale (VAPS) was used to measure self-report of patient pain. Complications were recorded for subsequent analysis. Results: VAPS scores for overall intraoperative pain ranged from 0 to $3(1.07 \pm 1.07)$ in group 1 , from 0 to $2(0.69 \pm 0.93)$ in group 2 and from 0 to $3(1.06 \pm 0.98)$ in group 3 . Assessment of surgeon discomfort score ranged from 0 to $2(0.31 \pm 0.66)$ in group 1 , from 0 to 3 $(0.38 \pm 0.82)$ in group 2 and from 0 to $2(0.47 \pm 0.62)$ in group 3 . Both scores reveal no significant difference among the 3 groups. While there were no complications noted in group 1 , there was an ocular perforation in group 2. Additionally,
\end{abstract}

there were no complications in group 3 related to the anesthetic technique. Conclusions: Results suggest that twostep anesthesia is a safe and effective anesthetic approach for selected patients undergoing 23- or 25-gauge pars plana vitrectomy or other posterior segment surgeries. It may offer a viable alternative to peribulbar anesthesia and retrobulbar anesthesia for carefully selected 23- or 25-gauge cannularaccess ocular surgeries.

(c) 2020 S. Karger AG, Basel

\section{Introduction}

The majority of patients undergoing eye surgeries report fear of ocular perforation and the anticipated pain from the surgery and related procedures. Anesthetic methods for ocular surgeries include general anesthesia and local anesthesia. Except for pediatric patients or very challenging cases (extremes of age, cases with severe systemic disease, dysgnosia, etc.), the majority of eye surgeries are performed under regional anesthesia [1]. This type of anesthesia includes different subtypes, such as topical anesthesia, subconjunctival anesthesia, retrobulbar anesthesia, peribulbar anesthesia, sub-Tenon's anesthesia and facial nerve block. Retrobulbar and peribulbar anesthesia karger@karger.com

www.karger.com/ore

(C) 2020 S. Karger AG, Base

Karger"
Wensheng $\mathrm{Li}$

Aier School of Ophthalmology, Central South University

No. 198 Furong Middle Road

Changsha, Hunan 410015 (China)

drlws@qq.com 

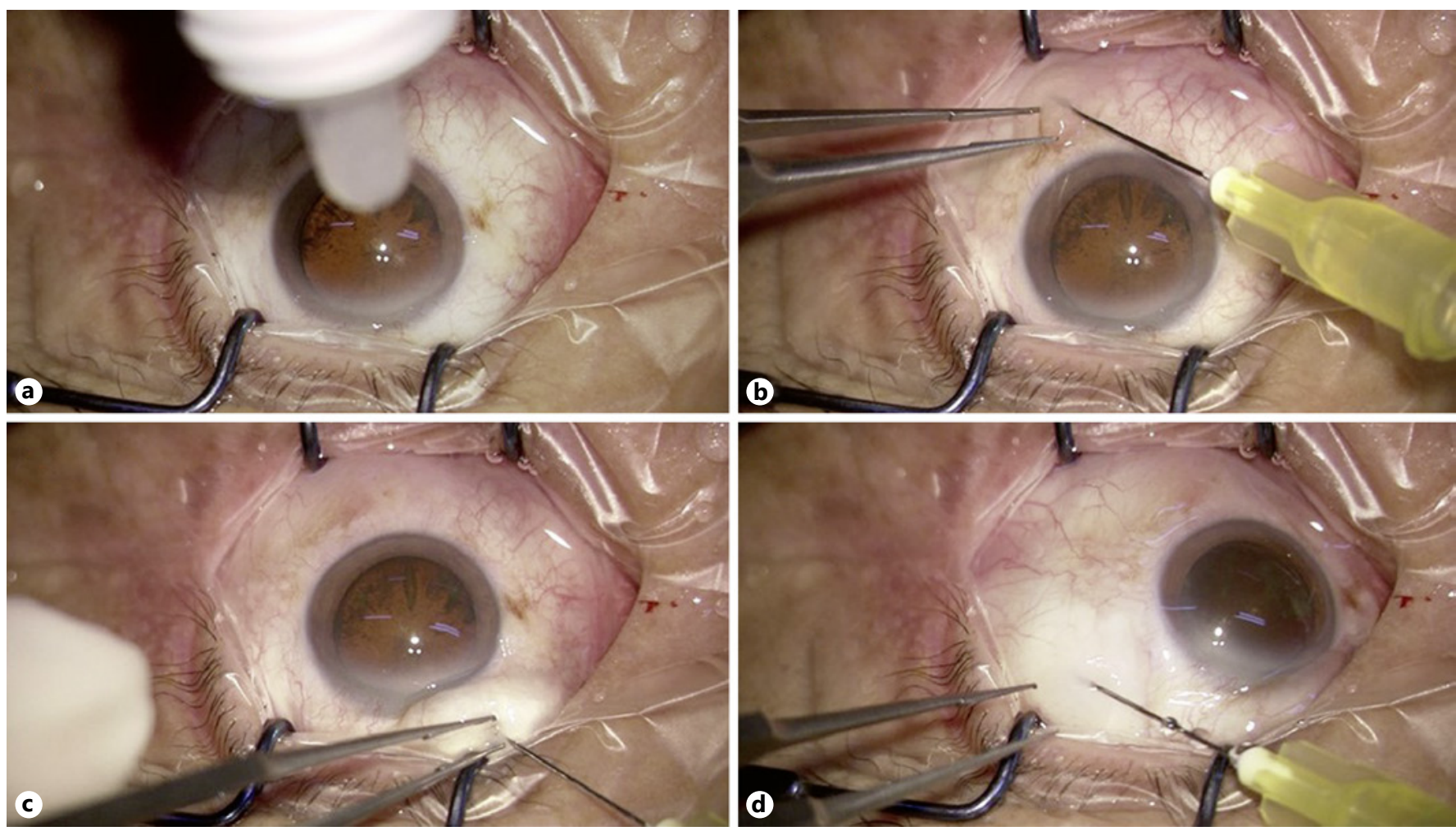

Fig. 1. Procedure illustration of two-step anesthesia. The conjunctival cul-de-sac is anesthetized with $0.5 \%$ proparacaine hydrochloride eyedrops (a); subconjunctival injection of $2 \%$ lidocaine is performed in the position of trocar insertion $(\mathbf{b}-\mathbf{d})$.

have a major role in ophthalmic surgery due to their provision of excellent analgesia and akinesia. However, these procedures are associated with major complications [2$5]$, such as scleral perforation $[6,7]$, retrobulbar hemorrhage [8], optic injury $[1,9]$, globe ischemia [9], oculocardiac reflex [9] and brainstem anesthesia [10-14].

In order to avoid such complications, topical anesthesia is used in many intraocular surgeries. The effectiveness and safety of topical anesthesia in cataract surgeries have been well demonstrated [15]. There are also several reports of vitreoretinal surgery being performed under topical anesthesia. Yepez et al. $[16,17]$ reported that topical anesthesia combined with neuroleptic anesthesia was a safe and effective alternative to peribulbar or retrobulbar anesthesia in posterior vitrectomy procedures. However, sedatives have potential risks of life-threatening cardiorespiratory complications and may obtund patient responses in the evaluation of pain levels during an operation. Kumar et al. [18] reviewed sedation-analgesia during cataract surgeries and reported that excessive sedation can impair the patient's ability to communicate verbally, reduce compliance and increase patient move- ment during surgery. It has also been reported that intraoperative sedation is associated with an increase in the number of adverse events reported during cataract surgery [19]. Furthermore, as one of topical anesthesia shortcomings, severe pain and discomfort occurred in a few patients when scleral indentation was performed [20, 21].

Subconjunctival anesthesia is often used in extraocular surgeries like curettage of chalazion but is not commonly used in intraocular surgeries. A single report about subconjunctival anesthesia applied in selected cases of vitrectomy showed satisfactory analgesia and no complications due to lack of akinesia. However, this study was not a comparative study, and the pain scores were not measured or reported [22].

To the best of our knowledge, there have been no literature reports comparing local anesthesia techniques with single-shot needle regional anesthesia. Thus, the purpose of our work was to conduct a prospective study to investigate the safety and efficacy of a new technique, termed "two-step anesthesia," which combines the use of topical and subconjunctival anesthesia. 
Table 1. Description of scales used in the current study

\begin{tabular}{llll}
\hline Score & Pain (VAPS) & Surgeon's discomfort (VASS) & Ocular movement \\
\hline 0 & No sensation/pain & Extremely comfortable & Akinesia \\
\hline 1 & Mild sensation/no pain & Mild movements/squeezing & Almost no movement \\
\hline 2 & Mild pain & $\begin{array}{l}\text { Moderate discomfort (significant ocular movements/ } \\
\text { squeezing/Bell's phenomenon) }\end{array}$ & Moderate movement \\
\hline 4 & Moderate pain & Severe discomfort hampering surgical maneuvering & Full movement \\
\hline
\end{tabular}

VAPS, visual analog pain scale; VASS, visual analog surgeon's discomfort scale.

\section{Materials and Methods}

This comparative, prospective, randomized study was approved by the Institutional Review Board of Shanghai Aier Eye Hospital. The study was registered as a clinical trial, and the identifier of trail registration on the website Clinicaltrials is NCT03577574; date of first registration was July 4, 2018.

The study was performed in accordance with the tenets of the Declaration of Helsinki. Patients $(n=90)$ with various vitreoretinal diseases were recruited from the Retina Department of Shanghai Aier Eye Hospital (Shanghai, China) between July 4, 2018, and January 1, 2019. Written informed consent was obtained from all participants. All patients were scheduled for posterior segment or combined surgeries (including vitrectomy, combined phacoemulsification-vitrectomy or silicone oil removal). Patients were excluded from the study if they had undergone posterior segment surgery within the past 3 months, had a known allergy to lidocaine or proparacaine, active ocular infection, mental retardation, claustrophobia or difficulty communicating, dementia, deafness or psychiatric illness. All patients were randomly assigned to one of 3 groups: group $1(n=29)$ received peribulbar anesthesia, group 2 $(n=29)$ received retrobulbar anesthesia and group $3(n=32)$ received two-step anesthesia (topical anesthesia plus subconjunctival anesthesia). No anxiolytics or sedatives were used in any group before or during surgery. Patients were blinded to their group distribution. Sample size was determined based on an analysis of the results from a previous pilot study with 15 patients per group. The average visual analog pain scale (VAPS) score was $1.1 \pm 1.0,1.0 \pm$ 1.1 and $1.6 \pm 0.8$ in groups 1,2 and 3 , respectively. When calculating the sample size, the aim was to find a significant difference in VAPS between the 3 groups. The calculation was based on a 2 -tailed test conducted with $\alpha=0.05$ and a power of $80 \%$ assuming a $5 \%$ dropout; therefore, the simple size was defined as $\geq 28$ patients per group [23]. A computer-generated randomization list was used to allocate random group assignment for each patient. A single investigator enrolled all participants and assigned them to interventions.

Prior to surgery, 5\% phenylephrine $\mathrm{HCl}$ and $1 \%$ tropicamide ophthalmic solutions were used for pupil dilation. Group 1 and 2 patients received approximately $4-6 \mathrm{~mL}$ of $2 \%$ lidocaine $\mathrm{HCl}$ into the peribulbar or retrobulbar space, respectively, via a 27-gauge, 32-mm Atkinson needle. After $30 \mathrm{~s}$, sensation was assessed by touching the cornea with a cotton swab and communicating with the patient. When the patient could no longer feel the cotton swab, the surgeon was informed to come into the operative room and surgery began; the time between injection and surgery onset was recorded.

In group 3, the conjunctival cul-de-sac was anesthetized with 3 drops of $0.5 \%$ proparacaine hydrochloride ophthalmic solution 10-15 min preceding surgery in the preoperative area. After sterilization and draping, a speculum was inserted and subconjunctival injections of about $0.15 \mathrm{~mL}$ (totally approx. $0.5-0.6 \mathrm{~mL}$ ) $2 \%$ lidocaine $\mathrm{HCl}$ were performed in the inferotemporal quadrant, superotemporal quadrant and inferonasal quadrant, via a 30-gauge needle as shown in Figure 1. After 3 min surgery began.

Postanesthesia ocular movement was evaluated preoperatively across the 4 quadrants of gaze directions. As presented in Table 1, the following 4-point scoring system was used: 3 (full movement), 2 (moderate movement), 1 (almost no movement) and 0 (akinesia) [24].

All anesthesia procedures were completed by an assistant (Z.Q., H.W. or D.L.) and all surgeries were completed by the same surgeon (W.L.) who was blind to the group allocation. All surgeries were done in a standardized fashion (3-port double system pars plana entry and infusion cannula in the lower temporal area) using the associated surgical systems and 23- or 25-gauge surgical instruments (Alcon Laboratories, Fort Worth, TX, USA). Vitrectomy was performed using an Alcon Constellation vitrectomy system. Cataract surgery, intraocular laser photocoagulation, fluid-air exchange or cryocoagulation were performed as needed. At the completion of all surgeries, the sclerotomy site was compressed with a cotton swab after removal of the cannula. If any leakage occurred, a suture was placed at the site of leakage.

All patients were asked to report pain levels in each step of the surgery by a nurse who was blind to group distribution, including pain felt at the time of anesthesia administration in groups 1 and 2. Patients were asked to inform if they felt unbearable pain (grade 3 ) at any time during the surgery. In such case, additional subconjunctival anesthesia or peribulbar anesthesia was given. If additional anesthesia was applied, this application was recorded, and the case was excluded from further analysis. As reported in Table 1, the surgeon's comfort and ease while performing the surgery were evaluated using a 5-point visual analog surgeon's discomfort scale (VASS), which rated comfort
36 
Table 2. Demographic data, eye laterality and surgery indications

\begin{tabular}{lccc}
\hline & Group 1 & Group 2 & Group 3 \\
\hline Demographic parameters & & & \\
$\quad$ Mean age \pm SD, years & $62.0 \pm 16.2$ & $60.2 \pm 12.1$ & $62.0 \pm 16.2$ \\
Sex, $n(\%)$ & $13(44.8)$ & $13(44.8)$ & $15(46.9)$ \\
Male & $16(55.2)$ & $16(55.2)$ & $17(53.1)$ \\
Female & $16(55.2)$ & $14(48.3)$ & $14(43.8)$ \\
Eye laterality, $n$ (\%) & $13(44.8)$ & $15(51.7)$ & $18(56.2)$ \\
Right eye & 11 & 10 & 12 \\
Left eye & 1 & 2 & 2 \\
Indications for surgery & 5 & 3 & 6 \\
Vitreous opacity & 1 & 0 & 1 \\
Macular hole & 2 & 3 & 1 \\
Epiretinal membrane & 7 & 10 & 6 \\
Retinoschisis & 0 & 1 & 3 \\
Silicone oil-filled eye & 2 & 0 & 1 \\
Retinal detachment & & & $2(6.2)$ \\
Proliferative diabetic retinopathy & $2(6.9)$ & $3(10.3)$ & $30(93.8)$ \\
Others & $27(93.1)$ & $26(89.7)$ & \\
Cannula system, $n$ (\%) & & & \\
23-gauge & & & \\
25-gauge & & & \\
\hline
\end{tabular}

Table 3. Pain levels and surgeon's discomfort

\begin{tabular}{lcccc}
\hline Parameters & Group 1 & Group 2 & Group 3 & $p$ value \\
\hline Pain level during surgery & $1.07 \pm 1.07$ & $0.69 \pm 0.93$ & $1.06 \pm 0.98$ & $0.207^{\mathrm{a}}$ \\
Postoperative pain at 1 h & $0.45 \pm 0.74$ & $0.39 \pm 0.57$ & $0.41 \pm 0.67$ & $0.995^{\mathrm{a}}$ \\
Postoperative pain at 24 h & $0.21 \pm 0.49$ & $0.17 \pm 0.47$ & $0.16 \pm 0.25$ & $0.395^{\mathrm{a}}$ \\
Surgeon's discomfort & $0.31 \pm 0.66$ & $0.38 \pm 0.83$ & $0.47 \pm 0.62$ & $0.286^{\mathrm{a}}$ \\
Ocular movement & $1.34 \pm 0.72$ & $0.82 \pm 0.91$ & $2.84 \pm 0.63$ & $<0.001^{\mathrm{a}}$ \\
Duration of surgery & $33.1 \pm 13.7$ & $37.5 \pm 20.6$ & $28.0 \pm 19.0$ & $0.155^{\mathrm{b}}$ \\
\hline
\end{tabular}

Mean pain levels $( \pm$ SD) based on VAPS scale recorded during surgery, 1 and $24 \mathrm{~h}$ postoperatively are shown. Additionally, mean values $( \pm \mathrm{SD})$ for surgeon's discomfort score (based on VASS scale), ocular movement score (see main text) and duration of surgery times (in minutes) for the 3 groups are presented. ${ }^{a}$ Kruskal-Wallis H test. ${ }^{b} \chi^{2}$ test.

from 0 (extremely comfortable) to 4 (unable to perform surgery under topical anesthesia) [20]. Each patient was provided explanation of the 5-point VAPS and graded their level of postoperative pain and discomfort. Any adverse events, including subconjunctival hemorrhage, chemosis, headache, nausea, vomiting, lid edema or ecchymosis, injury to optic nerve, globe perforation, cranial nerve palsies, diplopia, restrictive strabismus and ptosis, were recorded.

Statistical analysis was performed using a commercially available statistical software package (SPSS for Windows, version 19.0, SPSS Inc., Chicago, IL, USA). VAPS, VASS and ocular movement scores were compared between the groups using the Kruskal-Wallis $\mathrm{H}$ test, and surgery duration was compared using the $\chi^{2}$ test. A threshold for statistical significance was set at $p<0.05$.

\section{Results}

Consecutive patients $(n=90)$ underwent 23 - or 25 -gauge posterior segment, or combined, surgeries. As shown in Table 2, the 3 groups did not differ statistically in terms of age or gender $(p>0.05)$. All patients were of the same ethnicity (Han Chinese). The distribution pattern of trocar size was well-balanced among the 3 groups (Table 3).

The VAPS for overall intraoperative pain ranged from 0 to 3 (mean $=1.07 ; \mathrm{SD}=1.07$ ) in group 1 , from 0 to $2($ mean $=0.69 ; \mathrm{SD}=0.93)$ in group 2 and from 0 to 3 


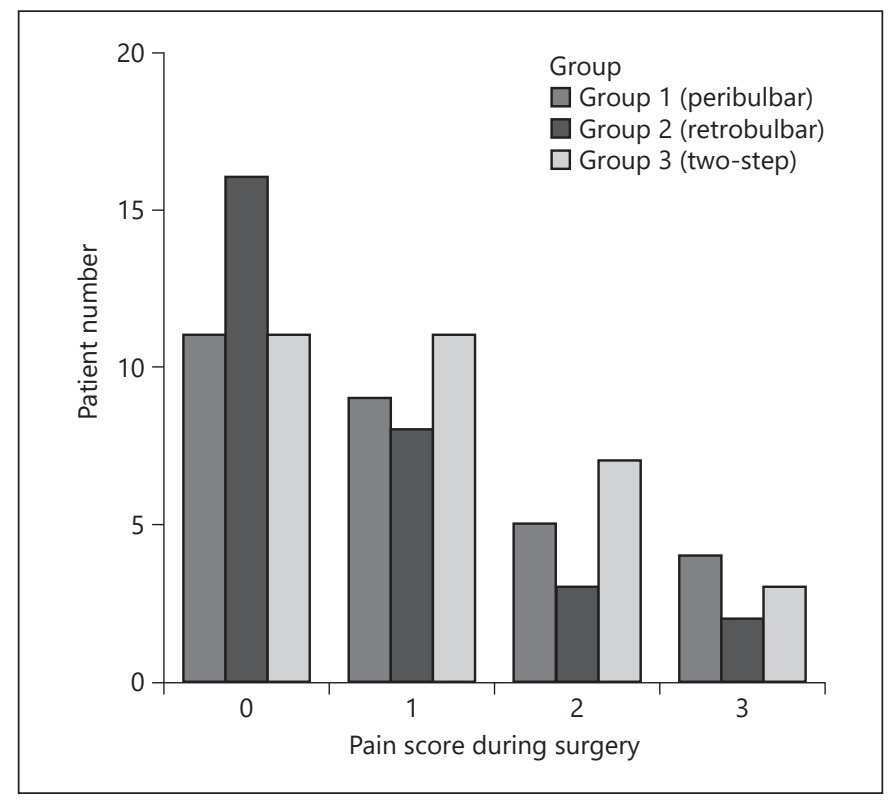

Fig. 2. Distribution of pain scores during surgery. The dark gray column represents the peribulbar anesthesia group, the black column the retrobulbar anesthesia group and the gray column the two-step anesthesia group.

$($ mean $=1.06 ; \mathrm{SD}=0.98)$ in group 3 (Table 3, Fig. 2$)$. The surgeon's discomfort VASS score ranged from 0 to 2 (mean $=0.31 ; \mathrm{SD}=0.66$ ) in the peribulbar group, from 0 to 3 (mean $=0.38 ; \mathrm{SD}=0.82$ ) in the retrobulbar group and from 0 to 2 (mean $=0.47 ; \mathrm{SD}=0.62)$ in the two-step group (Table 3, Fig. 3). The mean surgical time was $33.11 \pm 13.69$ min (range 15-69 min), $37.48 \pm 20.60 \mathrm{~min}$ (range 10-115 $\mathrm{min}$ ) and $28.03 \pm 19.03 \mathrm{~min}$ (range $10-110 \mathrm{~min}$ ) in groups 1,2 and 3, respectively. A comparison of group parameters is shown in Table 3. There was no significant difference in VAPS $(p=0.207)$, VASS $(p=0.286)$ or surgical time $(p=0.155)$ between the 3 groups.

In group $1(n=29)$, the worst pain was experienced during scleral indentation (grade 3 ). Grade 2 pain scores were also recorded during anesthesia $(n=3)$, trocar entry $(n=1)$ and cannula removal $(n=1)$. One patient who required additional anesthesia (single subconjunctival $2 \%$ lidocaine injection) was excluded from statistical analysis. None of the patients required postoperative oral analgesics. The average VAPS score at 1 and $6 \mathrm{~h}$ postoperatively was 0.45 and 0.21 , respectively (Table 3 ). Two patients presented with lid ecchymosis. There were no other adverse events associated with anesthesia and no other significant complications were noted.

In group $2(n=29)$, the worst pain was experienced during the retrobulbar injection and scleral indentation

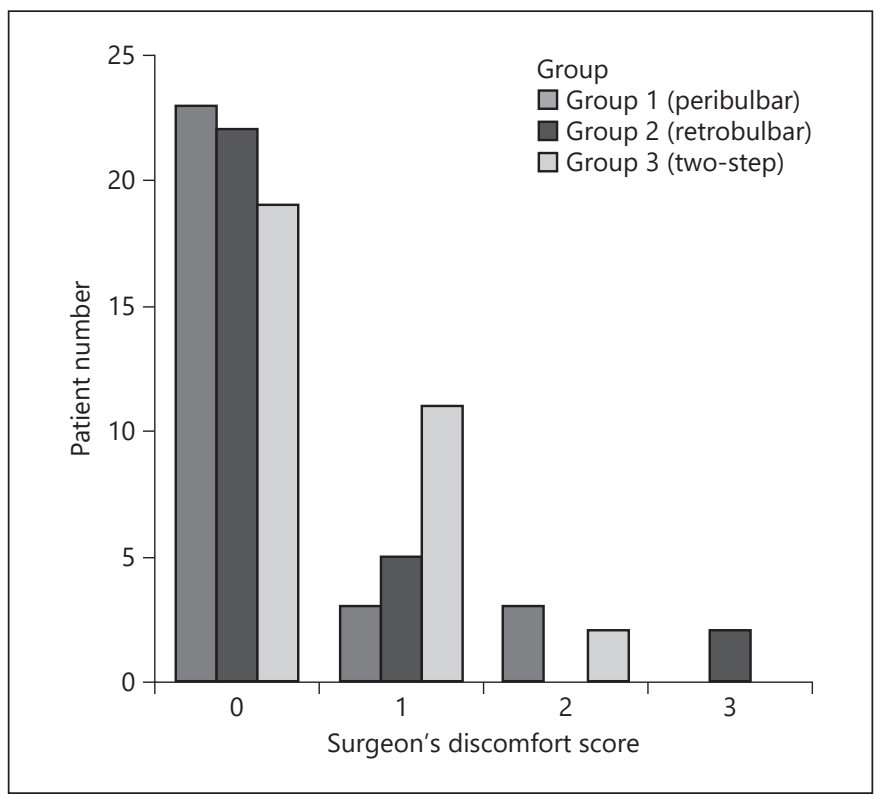

Fig. 3. Distribution of surgeon's discomfort scores during surgery. The dark gray column represents the peribulbar anesthesia group, the black column the retrobulbar anesthesia group and the gray column the two-step anesthesia group.

(grade 3). Patients reported a maximum of grade 2 pain during retrobulbar injection $(n=6$; mean $=1.83$; $\mathrm{SD}=$ 0.75 ; range $1-2$ ). Four patients presented with eyelid edema on the first postoperative day. Unfortunately, in $1 \mathrm{fe}-$ male patient (63 years, axial length $32.07 \mathrm{~mm}$ ), who underwent right vitrectomy combined with cataract surgery, a medial globe perforation with vitreous hemorrhage occurred, alongside a moderate ocular hypotony. The vitreous hemorrhage and hypotony were managed during surgery, with a final corrected vision of 20/200.

In group $3(n=32)$, the worst pain was experienced during subconjunctival injection $(n=5$; mean $=2.00$; $\mathrm{SD}=1.00$; range $1-3)$ and cannula removal $(n=1$; VAPS $=3$ ). Three patients reported grade 2 pain during cryocoagulation and 2 patients reported grade 2 level pain during intraocular laser photocoagulation. Four patients reported grade 1 pain level during trocar insertion and removal. There was no significant difference in reported pain between the 23- and 25-gauge vitrectomy. Most patients had conjunctival chemosis after anesthesia; the chemosis was reduced after cotton swab massage and did not hinder trocar-cannula placement. A subgroup of patients $(n=11)$ showed subconjunctival hemorrhage (no $>2$ sectors of the bulbar conjunctiva) and most of the hemorrhage resolved after 3-4 weeks. There were no other complications associated with the anesthesia. 
Table 4. Potentially pain-inducing procedures during surgery

\begin{tabular}{llll}
\hline Procedures & Group 1 & Group 2 & Group 3 \\
\hline Injection & $2.0 \pm 0.7(n=5)$ & $1.8 \pm 0.7(n=6)$ & $2.0 \pm 1.0(n=5)$ \\
Trocar insertion & $1.6 \pm 0.9(n=5)$ & $0.0(n=0)$ & $1.0(n=4)$ \\
Scleral indentation & $1.8 \pm 1.1(n=5)$ & $1.3 \pm 0.8(n=7)$ & $0.0(n=0)$ \\
Endolaser & $1.0(n=1)$ & $0.0(n=0)$ & $1.7 \pm 0.6(n=3)$ \\
Cryocoagulation & $1.0(n=1)$ & $0.0(n=0)$ & $1.7 \pm 0.5(n=4)$ \\
Cannula removal & $2.0(n=1)$ & $0.0(n=0)$ & $3.0(n=1)$ \\
Suture of leakage & $2.0(n=1)$ & $0.0(n=0)$ & $1.5 \pm 0.7(n=2)$ \\
Other ${ }^{1}$ & $0.0(n=0)$ & $0.0(n=0)$ & $1.0(n=3)$ \\
\hline
\end{tabular}

Mean values $( \pm S D)$ of VAPS for procedures during surgery in the 3 groups. ${ }^{1}$ Other procedure includes speculum placement, draping and surgical drape removal.
The average VAPS score $1 \mathrm{~h}$ postoperatively was 0.45 $\pm 0.74,0.39 \pm 0.57$ and $0.39 \pm 0.57$ in groups 1,2 and 3 , respectively. At $24 \mathrm{~h}$ following surgery, the average VAPS score was $0.21 \pm 0.49,0.17 \pm 0.47$ and $0.16 \pm 0.25$ in groups 1,2 and 3 , respectively (Table 3 ). There were no significant differences among the 3 groups with regard to VAPS score at both time points $(p>0.05)$. Average ocular movement scores were $1.34 \pm 0.72,0.82 \pm 0.91$ and $2.84 \pm 0.63$ in groups 1, 2 and 3, respectively. As expected, significant differences were found in average ocular movement scores among the 3 groups $(p<0.05)$, with group 3 showing greater ocular movement scores compared to groups 1 and 2.

Pain scores of each surgical step in groups are shown in Table 4. There was no significant difference of VAPS between the groups in anesthetic drug injection ( $p=$ $0.69)$. There was a significant difference between the groups in trocar insertion, scleral indentation, endolaser, cannular removal and suture of leakage steps of surgery (all $p<0.05)$. In group 3, patients experienced more pain and discomfort than groups 1 and 2 during endolaser, cryocoaculation and cannula removal steps of surgery. However, the pain experienced during scleral indentation in group 3 was less than in groups 1 and 2, and the pain experienced during trocar insertion in group 3 was less than in group 1.

\section{Discussion/Conclusion}

In this study, different anesthetic techniques for posterior segment or combined posterior segment plus cataract surgery were investigated. Using the two-step anesthesia method, nearly $85 \%$ of patients $(n=27)$ felt no pain from the injection, and $88 \%$ of patients $(n=28)$ felt no obvious pain and discomfort during trocar insertion and removal. Additionally, $68.75 \%$ of patients reported no pain or only perception of touch during surgery, and $97 \%$ patients were satisfied with the procedure. These findings were compared to the findings in patients undergoing surgery using retrobulbar and peribulbar anesthesia; twostep anesthesia showed no significant difference in pain level scores during surgery, $1 \mathrm{~h}$ or 1 day postoperatively as compared to the other methods. There was no difference in self-reported surgical discomfort across the 3 groups.

Retrobulbar anesthesia and peribulbar anesthesia are the most frequently utilized local anesthesia techniques for vitrectomy or other eye surgeries. Retrobulbar anesthesia can provide satisfactory analgesia and akinesia. However, the needle tip is invisible during both procedures. A report which compared retrobulbar anesthesia and subconjunctival anesthesia for cataract surgery also indicated that since retrobulbar anesthesia induced a high reduction of blood flow velocity in the retrobulbar vessels in contrast to subconjunctival anesthesia, subconjunctival anesthesia may be a good alternative particularly for patients with problems with ocular perfusion (e.g., glaucoma) [25]. Schrader et al. [26] reported cases of sclera perforation $(n=9)$ during retrobulbar or peribulbar injection. The majority of patients were left with only ambulatory vision. In the present study, one ocular perforation during retrobulbar anesthesia was noted. The axial length of this patient was $>32 \mathrm{~mm}$, and posterior staphyloma was present. A globe with high myopia and posterior staphyloma is more likely to be perforated during peribulbar/retrobulbar anesthesia [26]. On the other hand, if the anesthesia is given by a subconjunctival injection, where the tip of the needle is visible, globe perforation may be avoided. 
There are several reports of vitreoretinal surgery and combined phacoemulsification vitrectomy being performed under topical anesthesia [16, 21, 27-30]. Yepez et al. $[16,17]$ reported that topical anesthesia, combined with neuroleptic anesthesia, was a safe and effective alternative to peribulbar or retrobulbar anesthesia in posterior vitrectomy procedures. Wu et al. [21] assessed the effect of topical anesthesia in 27-gauge vitrectomy for vitreous floaters, and found topical anesthesia was as effective as peribulbar anesthesia. However, these studies were performed in a highly select group of patients requiring simple vitrectomy where most cases were comprised of symptomatic vitreous floaters, macular disorders or simple vitreous hemorrhages. Some studies showed a higher pain level in topical anesthesia compared to retrobulbar or peribulbar blocks for small gauge vitrectomy, especially during trocar insertion and removal [20,21]. Chaudhary et al. [28] reported the mean pain score in topical anesthesia was significantly higher as compared to peribulbar anesthesia in 23-gauge vitrectomy for vitreous hemorrhage. Moreover, in the study of Tang et al. [31], the authors reported their impression that indentation of the ciliary body and complete removal of the base vitreous was difficult under topical anesthesia. In the present study, complicated posterior segment surgeries, such as for retinal detachment or diabetic retinopathy, were not excluded. Furthermore, with regard to topical anesthesia, the worst pain was always reported in published studies during trocar insertion $[20,21,32]$, which did not happen in our study using two-step anesthesia. The most likely reason is that subconjunctival lidocaine injection used with two-step anesthesia provided better analgesia compared to topical anesthesia only. Based on our results, this new two-step anesthetic technique appears adequate for select vitreoretinal surgeries.

Two-step anesthesia uses a visible needle application technique, where the operator can see the tip clearly when placing the needle into the subconjunctival space. In this study, no severe complications were noted in the two-step anesthesia group. The average pain level during surgery was not statistically different between the groups despite some slight variations in the mean score. Although the two-step anesthesia method could be safer by avoiding injury to the optic nerve and the back of the eye when compared to peribulbar or retrobulbar anesthesia, this technique did not produce ocular akinesia in the present study, with most patients demonstrating free ocular movement during the operation. While some patients could follow the surgeon's orders, which facilitated the procedure, ocular movement increased the difficulty in patients with poor cooperation. Despite these difficulties, in group 3, all surgeries were completed without any major complications. Due to the absence of akinesia and the potential for limited patient cooperation, we suggest that (1) the two-step anesthesia method should be used in carefully selected cases and (2) the surgeon must be well experienced in vitrectomy. It has to be kept in mind that despite the perceived risk of akinesia, application of topical anesthesia alone also results in lack of akinesia but is unlikely to cause sight-threatening complications during cataract surgery [33], vitrectomy [20,21, 27, 28, 32, 34, 35 ], combined phacoemulsification and vitrectomy [29], or vitrectomy-related procedures, like fluid-gas exchange for open macular hole after vitrectomy [36]. A 2-year prospective study comparing lidocaine $2 \%$ jelly versus peribulbar anesthesia for 25- and 23-gauge sutureless vitrectomy also indicated that lack of akinesia did not prevent a successful surgical result [37]. Furthermore, in a study of vitreoretinal procedures under topical anesthesia, the majority of surgeons (85.29\%) reported to feel very comfortable during operations [34].

There are some limitations of this study. First, as there was subconjunctival hemorrhage or edema in subconjunctival anesthesia but not in retrobulbar or peribulbar anesthesia, the surgeon may have been not fully masked to the anesthesia grouping, which may have introduced some bias in the surgeon's discomfort scores. However, patients were unaware of such differences, and, therefore, it would not have influenced patients' pain scores which was the primary outcome measure of this study. Second, we conclude that two-step anesthesia is inadequate for complex and lengthy posterior compartment surgeries like in cases of severe proliferative vitreoretinopathy, ocular tumors, severe proliferative diabetic retinopathy and complicated ocular trauma, where retrobulbar anesthesia, which provides both analgesia and akinesia is more suitable. At this point, it appears that two-step anesthesia is not adequate for highly complicated cases with longerthan-expected surgical time surgeries. Third, the distribution of potentially pain-causing procedures within each group was not completely balanced (Table 4). For example, neither endolaser nor cryocoagulation were present in group 2 and were overrepresented in group 3 versus 1 , which has the potential to influence the mean pain score.

In summary, two-step anesthesia appears to be a safe anesthetic technique for select simple ocular surgeries
40

Ophthalmic Res 2021;64:34-42 DOI: $10.1159 / 000508510$
Fan/Qian/Tzekov/Lin/Wang/Li 
with no significant difference in pain score and intraoperative surgeon comfort when compared with alternate single-shot needle regional techniques.

\section{Statement of Ethics}

This study adhered to the tenets of the Declaration of Helsinki and was approved by the Institutional Review Board of Shanghai Aier Eye Hospital.

\section{Disclosure Statement}

The authors declare no competing financial interests.

\section{Funding Sources}

This study was funded by the National Natural Science Foundation of China (No. 81570875), Science Research Foundation of Aier Eye Hospital Group (grant No. AFM1701D3) and the Technology Innovation Program of Hunan Province (grant No. 2017SK50901). The funding organizations had no role in the design or conduct of this research.

\section{Author Contributions}

W.L. and H.F.: conception and design. H.F., H.W., D.L. and Z.Q.: data collection. H.F., Z.Q., D.L. and R.T.: analysis and interpretation. H.F., Z.Q., W.L. and R.T.: manuscript preparation. H.F. and W.L.: obtained funding. H.F., Z.Q., W.L., D.L. and H.W.: overall responsibility. All authors reviewed the paper.

\section{References}

1 Jaichandran V. Ophthalmic regional anaesthesia: A review and update. Indian J Anaesth. 2013 Jan;57(1):7-13.

2 Ascaso FJ, Peligero J, Longás J, Grzybowski A. Regional anesthesia of the eye, orbit, and periocular skin. Clin Dermatol. 2015 Mar-Apr; 33(2):227-33.

3 McGoldrick KE. Complications of regional anesthesia for ophthalmic surgery. Yale J Biol Med. 1993 Sep-Oct;66(5):443-5.

4 Morgan CM, Schatz H, Vine AK, Cantrill HL, Davidorf FH, Gitter KA, et al. Ocular complications associated with retrobulbar injections. Ophthalmology. 1988 May;95(5):6605.

5 Weiss JL, Deichman CB. A comparison of retrobulbar and periocular anesthesia for cataract surgery. Arch Ophthalmol. 1989 Jan; 107(1):96-8.

6 Duker JS, Belmont JB, Benson WE, Brooks HL Jr, Brown GC, Federman JL, et al. Inadvertent globe perforation during retrobulbar and peribulbar anesthesia. Patient characteristics, surgical management, and visual outcome. Ophthalmology. 1991 Apr;98(4):51926.

7 Hay A, Flynn HW Jr, Hoffman JI, Rivera AH. Needle penetration of the globe during retrobulbar and peribulbar injections. Ophthalmology. 1991 Jul;98(7):1017-24.

8 Takaschima A, Marchioro P, Sakae TM, Porporatti AL, Mezzomo LA, De Luca Canto G. Risk of hemorrhage during needle-based ophthalmic regional anesthesia in patients taking antithrombotics: a systematic review. PLoS One. 2016 Jan;11(1):e0147227.

9 Faccenda KA, Finucane BT. Complications of regional anaesthesia Incidence and prevention. Drug Saf. 2001;24(6):413-42.

10 Rubin AP. Complications of local anaesthesia for ophthalmic surgery. Br J Anaesth. 1995 Jul;75(1):93-6.
11 Clarke JP, Plummer J. Adverse events associated with regional ophthalmic anaesthesia in an Australian teaching hospital. Anaesth Intensive Care. 2011 Jan;39(1):61-4.

12 Edge KR, Davis A. Brainstem anaesthesia following a peribulbar block for eye surgery. Anaesth Intensive Care. 1995 Apr;23(2):219-21.

13 Hamilton RC. Brain stem anesthesia following retrobulbar blockade. Anesthesiology. 1985 Dec;63(6):688-90.

14 Javitt JC, Addiego R, Friedberg HL, Libonati MM, Leahy JJ. Brain stem anesthesia after retrobulbar block. Ophthalmology. 1987 Jun; 94(6):718-24.

15 Malik A, Fletcher EC, Chong V, Dasan J. Lo$\mathrm{cal}$ anesthesia for cataract surgery. J Cataract Refract Surg. 2010 Jan;36(1):133-52.

16 Yepez J, Cedeño de Yepez J, Arevalo JF. Topical anesthesia in posterior vitrectomy. Retina. 2000;20(1):41-5.

17 Yepez J, Cedeno de Yepez J, Arevalo JF. Topical anesthesia for phacoemulsification, intraocular lens implantation, and posterior vitrectomy. J Cataract Refract Surg. 1999 Aug; 25(8):1161-4.

18 Kumar CM, Seet E, Eke T, Irwin MG, Joshi GP. Peri-operative considerations for sedation-analgesia during cataract surgery: a narrative review. Anaesthesia. 2019 Dec;74(12): 1601-10.

19 Katz J, Feldman MA, Bass EB, Lubomski LH, Tielsch JM, Petty BG, et al.; Study of Medical Testing for Cataract Surgery Study Team. Adverse intraoperative medical events and their association with anesthesia management strategies in cataract surgery. Ophthalmology. 2001 Oct;108(10):1721-6.

20 Mahajan D, Sain S, Azad S, Arora T, Azad R. Comparison of topical anesthesia and peribulbar anesthesia for 23-gauge vitrectomy without sedation. Retina. 2013 Jul-Aug;33(7): 1400-6.
21 Wu RH, Zhang R, Lin Z, Liang QH, Moonasar N. A comparison between topical and retrobulbar anesthesia in 27-gauge vitrectomy for vitreous floaters: a randomized controlled trial. BMC Ophthalmol. $2018 \mathrm{Jul}$; 18(1): 164 .

22 Malik AI, Foster RE, Correa ZM, Petersen MR, Miller DM, Riemann CD. Anatomical and visual results of transconjunctival sutureless vitrectomy using subconjunctival anesthesia performed on select patients taking anticoagulant and antiplatelet agents. Retina. 2012 May;32(5):905-11.

23 Carneiro AV. Estimating sample size in clinical studies: basic methodological principles. Rev Port Cardiol. 2003 Dec;22(12):1513-21.

24 Zhou YL, Tong Y, Wang YX, Zhao PQ, Wang ZY. A prospective, randomised, doublemasked comparison of local anaesthetic agents for vitrectomy. Br J Ophthalmol. 2017 Aug;101(8):1016-21.

25 Huber KK, Remky A. Effect of retrobulbar versus subconjunctival anaesthesia on retrobulbar haemodynamics. Br J Ophthalmol. 2005 Jun;89(6):719-23.

26 Schrader WF, Schargus M, Schneider E, Josifova T. Risks and sequelae of scleral perforation during peribulbar or retrobulbar anesthesia. J Cataract Refract Surg. 2010 Jun; 36(6):885-9.

27 Bahçecioglu H, Unal M, Artunay O, Rasier R, Sarici A. Posterior vitrectomy under topical anesthesia. Can J Ophthalmol. 2007 Apr; 42(2):272-7.

28 Chaudhary RA, Khaqan HA, Ahmad A, Imtiaz U, Raza H, Shabbir U. Comparison of topical versus peribulbar anesthesia for $23 \mathrm{G}$ pars plana vitrectomy. J Coll Physicians Surg Pak. 2018 Jun;28(6):452-5. 
29 Lam DS, Leung HY, Liu S, Radke N, Yuan Y, Lee VY. Two-port pars plana anterior and central core vitrectomy (lam floaterectomy) in combination with phacoemulsification and intraocular lens implantation under topical anesthesia for patients with cataract and significant floaters: results of the first 50 consecutive cases. Asia Pac J Ophthalmol (Phila). 2017 Jan-Feb;6(1):33-6.

30 Mete A, Saygllı O, Kimyon S, Pamukcu C, Çeri S, Güngör K, et al. Comparison of pain experience during $23-\mathrm{G}$ vitreoretinal surgery under topical and retrobulbar anesthesia. Int Ophthalmol. 2017 Apr;37(2):349-56.

31 Tang S, Lai P, Lai M, Zou Y, Li J, Li S. Topical anesthesia in transconjunctival sutureless 25 -gauge vitrectomy for macular-based disorders. Ophthalmologica. 2007;221(1):65-8.
32 Celiker H, Karabas L, Sahin O. A comparison of topical or retrobulbar anesthesia for 23-gauge posterior vitrectomy. J Ophthalmol. 2014;2014:237028.

33 Eke T, Thompson JR. Serious complications of local anaesthesia for cataract surgery: a 1 year national survey in the United Kingdom. Br J Ophthalmol. 2007 Apr;91(4):470-5.

34 Trujillo-Sanchez GP, Gonzalez-De La Rosa A, Navarro-Partida J, Haro-Morlett L, Altamirano-Vallejo JC, Santos A. Feasibility and safety of vitrectomy under topical anesthesia in an office-based setting. Indian $\mathrm{J}$ Ophthalmol. 2018 Aug;66(8):1136-40.
35 Lin Z, Moonasar N, Wu RH, Seemongal-Dass RR. 27-gauge vitrectomy for symptomatic vitreous floaters with topical anesthesia. Case Rep Ophthalmol. 2017 Jan;8(1):35-9.

36 Rao X, Wang N-K, Chen Y-P, Hwang Y-S, Chuang L-H, Liu I-C, et al. Outcomes of outpatient fluid-gas exchange for open macular hole after vitrectomy. Am J Ophthalmol. 2013 Aug;156(2):326-33.e1.

37 Theocharis IP, Alexandridou A, Tomic Z. A two-year prospective study comparing lidocaine $2 \%$ jelly versus peribulbar anaesthesia for $25 \mathrm{G}$ and $23 \mathrm{G}$ sutureless vitrectomy. Graefes Arch Clin Exp Ophthalmol. 2007 Sep; 245(9):1253-8. 